\title{
Loss of the third upper premolar in Suncus murinus and its relation to jaw size
}

\author{
Masahito NATORI and Nobuo SHIGEHARA
}

\begin{abstract}
Natori M. and Shigehara N. 1997. Loss of the third upper premolar in Suncus murinus and its relation to jaw size. Acta Theriologica 42: 99-104.

Musk shrew Suncus murinus (Linnaeus, 1766) has a very reduced $\mathrm{P}^{3}$, and it is often missing. Hanamura (1985), based on a sample from Okinawa Island, proposed that the high incidence in $\mathrm{P}^{3}$ loss was a distinguishing characteristic of musk shrew. However, while the Okinawa population lacked $\mathrm{P}^{3}$ in 26 of 95 individuals $(27.4 \%)$, specimens from Taiwan showed no $\mathrm{P}^{3}$ loss. Thus, the high incidence of $\mathrm{P}^{3}$ loss is not one of distinguishing characteristic of musk shrews. In the Okinawa sample, $\mathrm{P}^{4}-\mathrm{M}^{3}$ length vs palatal length in the group with $\mathrm{P}^{3}$ on both sides was significantly greater than that without $\mathrm{P}^{3}$. The relationship between the $\mathrm{P}^{4}-\mathrm{M}^{3}$ and palatal lengths showed negative allometry (Okinawa population with $\mathrm{P}^{3}: y=0.18+0.67 x$; Okinawa population without $\mathrm{P}^{3}: y=0.21+0.67 x$; Taiwan population: $y=0.15+0.68 x$ ). Taiwan population had a greater $\mathrm{P}^{4}-\mathrm{M}^{3}$ length relative to palatal length than did the Okinawa population because palatal length was greater in the former. These findings suggest that, as in the case of human third molars, a reduction in upper jaw size is responsible for the loss of the third molar in the Okinawa musk shrews.

Faculty of Science, Okayama University of Science, 1-1 Ridai-Cho, Okayama 700, Japan, E-mail: natori@das.ous.ac.jp (MN); Department of Evolution and Phylogeny, Primate Research Institute, Kyoto University, Kanrin, Inuyama 484, Japan (NS)
\end{abstract}

Key words: Suncus murinus, loss of tooth, allometry, dental anomalies

\section{Introduction}

The musk shrew Suncus murinus (Linnaeus, 1766) usually has two premolars (Allen 1938, Hanamura et al. 1978, Hanamura 1985). Its third upper premolar $\left(\mathrm{P}^{3}\right)$, when present, is greatly reduced and conical in shape (Fig. 1) (Hanamura et al. 1978, Hanamura 1985). According to Hanamura (1985), the incidence of $\mathrm{P}^{3}$ absence in the musk shrew is much higher than in other shrews. Furthermore, he suggested that this high incidence is one characteristic by which musk shrew can be distinguished from other shrews (Hanamura 1985). However, we observed that the frequency in $\mathrm{P}^{3}$ loss differed between musk shrew local populations. The primary purpose of this study was to evaluate the difference in $\mathrm{P}^{3}$ loss between the Okinawa and Taiwan musk shrew populations.

The human third molar is a typical example of tooth reduction, in which a simplification of shape and a decrease in size have occurred during a long period of evolution (Frisch 1965). In modern humans, the third molar is sometimes 


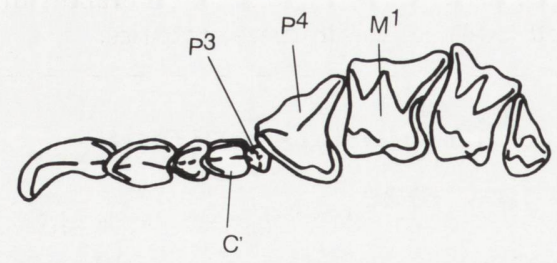

Fig. 1. Illustration of left upper dentition of musk shrew.

missing, and the incidence of loss varies between races and even, it appears, between populations of same race (Dahlberg 1949). Furthermore, human jaw as well as molar size have decreased (Gregory 1921, Martin 1990). Jaw size has decreased much more rapidly than postcanine dentition size (Gould 1975). Presumably, selection for two relatively large molars in a shortening jaw sometimes leads to the loss of the third molar in humans (eg Inoue 1980, Taylor 1982). This has generally been accepted as the reason for third molar loss in modern humans. Like modern humans, it is possible that $\mathrm{P}^{3}$ loss in musk shrews is related to discrepancy between its postcanine dental formula and jaw size (Shigehara 1980). A secondary purpose of this study was to test Shigehara's hypothesis.

\section{Materials and methods}

Shrews were collected from the field using Sherman live-traps. Sites and dates of the collections are as follows: Matanbashi $\left(26^{\circ} 11^{\prime} \mathrm{N}, 127^{\circ} 42^{\prime} \mathrm{E}\right)$ in Village of Tomigusuku and Kyozuka $\left(26^{\circ} 13^{\prime} \mathrm{N}\right.$, $\left.127^{\circ} 43^{\prime} \mathrm{E}\right)$ in Urasoe City on Okinawa from 23 January to 1 February 1976 ; in Tainan City $\left(23^{\circ} 01^{\prime} \mathrm{N}\right.$, $120^{\circ} 14^{\prime} \mathrm{E}$ ) on Taiwan from $25-30$ January 1976 . Skulls were cleaned using dermastid beetles.

We followed identification established by Allen (1938) and Hanamura et al. (1978) in dental class of musk shrew for the present study. In order to determine whether $\mathrm{P}^{3}$ was present but unerupted, we selected a random sample of 5 specimens devoid of $\mathrm{P}^{3}$ on both sides of the jaw for X-ray study. All specimens were negative for embedded $\mathrm{P}^{3}$.

We used palatal length and $\mathrm{P}^{4}-\mathrm{M}^{3}$ length respectively as measures of upper jaw size and postcanine size. Palatal length and left $\mathrm{P}^{4}-\mathrm{M}^{3}$ length were measured using a digital slide caliper (Mitsutoyo). We compared samples having $\mathrm{P}^{3}$ on both sides $\left(\mathrm{P}^{3}\right.$-present group) to samples without $\mathrm{P}^{3}$ on the both sides $\left(\mathrm{P}^{3}\right.$-absent group) with respect to palatal and $\mathrm{P}^{4}-\mathrm{M}^{3}$ lengths. Although seasonal changes in cranial size have been reported in some shrews (Pucek 1963, Louch et al. 1966), in the present study, it was possible to neglect seasonal variation since all shrews were collected in winter. In addition, age variations in cranial size of some shrews have been noted (eg Abe 1958). In the musk shrew, there has been little information on the process of cranial growth (see Shigehara 1980). Therefore, it is difficult to know with certainty the ages of the specimens examined here. We decided to measure crania in which all sutures were completely fused and teeth, especially incisors, were only lightly worn. Thus, we believe that the specimens used in the present study were similar to one another in terms of age and that our specimens may be classified as adults based on Abe's (1958) criteria.

We used a $G$-test to test for independence in a contingency table and an analysis of variance (ANOVA) to test for equality of means. We also examined the allometric relationships between the $\mathrm{P}^{4}-\mathrm{M}^{3}$ and palatal lengths. These analyses were performed after all variables had been converted into natural logarithms. Values of the isometry slopes were 1 since the abscissas and ordinates rep- 
resented lengths. In addition, we used an analysis of covariance (ANCOVA) to test for differences in the Y-intercept. We followed the methods of Sokal and Rohlf (1981) to obtain these statistics.

\section{Results}

In the Okinawa sample, 18 of $95(18.9 \%)$ shrews exhibited $\mathrm{P}^{3}$ loss on both sides and $8(8.4 \%)$ on only one side. $\mathrm{P}^{3}$ was absent on one side or both sides in 26 of 95 crania studied $(27.4 \%)$. On the other hand, in the Taiwan population, no $\mathrm{P}^{3}$ loss was noted in the 106 specimens examined. The difference in frequency between the Okinawa and Taiwan populations was statistically significant $(p<0.001)$.

We also compared the palatal and $\mathrm{P}^{4}-\mathrm{M}^{3}$ lengths (Table 1 ) among $\mathrm{P}^{3}$-present and $\mathrm{P}^{3}$-absent groups of Okinawa population, and Taiwan population using the Tukey-Kramer honestly significant difference test. These three groups showed significant differences between pairs of means $(p<0.05,0.01$ or 0.001$) . \mathrm{P}^{3}$-present and $\mathrm{P}^{3}$-absent groups of the Okinawa population, and Taiwan population showed increasing size in the order indicated (Table 1).

Table 1. Basic statistics of the cranial measurements, in $\mathrm{mm}$.

\begin{tabular}{|c|c|c|c|c|c|c|c|c|c|c|c|c|}
\hline \multirow{2}{*}{ Measurement } & \multicolumn{4}{|c|}{ Okinawa, $\mathrm{P}^{3}$-absent } & \multicolumn{4}{|c|}{ Okinawa, $\mathrm{P}^{3}$-present } & \multicolumn{4}{|c|}{ Taiwan, $\mathrm{P}^{3}$-present } \\
\hline & $n$ & Mean & SD & Range & $n$ & Mean & $\mathrm{SD}$ & Range & $n$ & Mean & SD & Range \\
\hline Palatal length & 18 & 14.53 & 0.51 & $13.61-15.22$ & 69 & 14.03 & 0.68 & $12.59-15.35$ & 106 & 15.51 & 0.74 & $13.97-17.14$ \\
\hline $\mathrm{P}^{4}-\mathrm{M}^{3}$ length & 18 & 7.32 & 0.20 & $6.88-7.51$ & 69 & 7.06 & 0.27 & $6.30-7.56$ & 106 & 7.53 & 0.28 & $6.81-8.40$ \\
\hline
\end{tabular}

We also analyzed the allometric relationship between $\mathrm{P}^{4}-\mathrm{M}^{3}$ and palatal lengths in $\mathrm{P}^{3}$-present and $\mathrm{P}^{3}$-absent groups for Okinawa population, and Taiwan population (Fig. 2). Correlation coefficients were significant $(p<0.001)$ and showed high values ( $\mathrm{P}^{3}$-present group: $0.85 ; \mathrm{P}^{3}$-absent group: 0.87 ; and Taiwan population: 0.88 ). Studies of within-group tooth versus skull scaling have shown low correlation coefficients in some human populations as well as for non-human primates (eg Kay 1975, Shea and Gomez 1988). These results differ from those of the musk shrew. In the regression equations for the $\mathrm{P}^{3}$-absent group, $\mathrm{P}^{3}$-present group and Taiwan population, the slopes varied significantly from zero at the 0.001 confidence level, and there were no significant outliers from this regression line based on a Durbin-Watson test. Since the exponents for the three groups were significantly smaller than $1(p<0.01)$, the relationships between the two dimensions in the three groups indicated negative allometry. Because all of the slopes were similar $(p>0.05)$, it is possible to compare Y-intercepts using ANCOVA between the three groups. The $\mathrm{Y}$-intercept for the $\mathrm{P}^{3}$-absent group was significantly larger $(p<0.05$ or 0.01 ) than those of both the Okinawa $\mathrm{P}^{3}$-present group and the Taiwan 


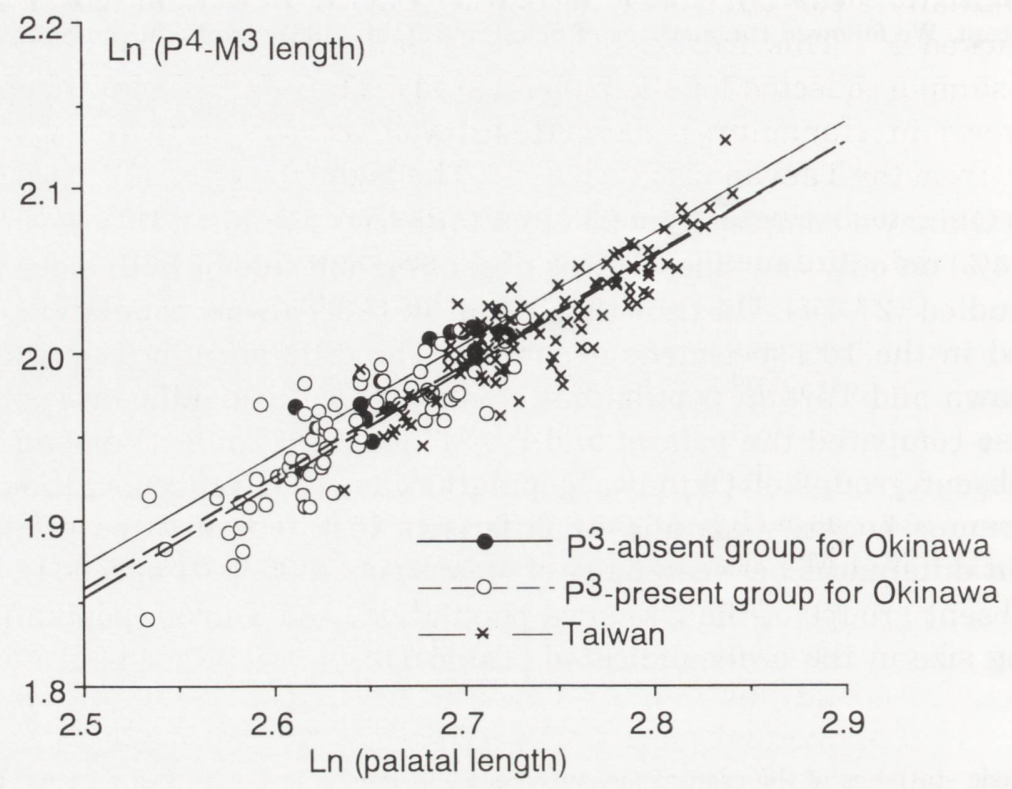

Fig. 2. Scatterplots of the $\mathrm{P}^{4}-\mathrm{M}^{3}$ length against palatal length in the $\mathrm{P}^{3}$-absent and $\mathrm{P}^{3}$-present groups collected on Okinawa and Taiwan. Regression equations: $\mathrm{P}^{3}$-present group: $y=0.18+0.67 x$; $\mathrm{P}^{3}$-absent group: $y=0.21+0.67 x$; Taiwan population: $y=0.15+0.68 x$.

population, but the latter two groups were not different significantly from each other $(p>0.05)$. This result shows that the $\mathrm{P}^{3}$-absent group has a larger postcanine tooth size relative to upper jaw size than does the Okinawa $\mathrm{P}^{3}$-present group and the Taiwan population, which are similar to each other.

\section{Discussion}

Allen (1938) and Hanamura et al. (1978) calculated the upper premolar number of the musk shrew to be two. Conversely, Sharma (1958) pointed out that upper premolar number was three. Allen (1938) and Hanamura et al. (1978) treated second premolar of Sharma (1958) as the canine (Isomura et al. 1984). We followed identification established by Allen (1938) and Hanamura et al. (1978) in dental class of musk shrew for the present study.

Hall (1940) examined the dental morphology of many shrews other than the musk shrew, and reported only rare cases where teeth were missing in these other shrews. In the musk shrew, on the other hand, many individuals lacked $\mathrm{P}^{3}$ in Hanamura's samples (Hanamura 1985). Hence, Hanamura (1985) proposed that the high incidence of $\mathrm{P}^{3}$ loss was a distinguishing characteristic of Suncus murinus. Hanamura (1985) collected and examined musk shrews in the southern 
part of Okinawa near our collecting sites, and observed that 10 of 40 shrews $(25.0 \%)$ lacked $\mathrm{P}^{3}$. This frequency is very similar to the value $(27.4 \%)$ for the Okinawa sample collected for the present study. Thus, the Okinawa population of musk shrews in Hanamura's samples as well as ours coincide, while all the specimens from the Taiwan sample had $\mathrm{P}^{3}$. The high incidence of $\mathrm{P}^{3}$ loss, therefore, can not be used to distinguish Suncus murinus from other shrews, but rather may be a characteristic unique to this species in southern Okinawa.

In modern humans, the third molar is the most unpredictable tooth in form and is the last of the postcanine teeth to erupt (Kraus et al. 1980). The situation is very similar to that of $\mathrm{P}^{3}$ for the musk shrew (Shigehara 1980, Hanamura 1985). The discrepancy between tooth and jaw sizes presumably led to reduction or loss of the third molar in modern humans (Inoue 1980). If overcrowding caused $\mathrm{P}^{3}$ loss in the musk shrew as it did in humans, a population without $\mathrm{P}^{3}$ should be larger in $\mathrm{P}^{4}, \mathrm{M}^{1}, \mathrm{M}^{2}$, and $\mathrm{M}^{3}$ total size relative to upper jaw size than one with $\mathrm{P}^{3}$. In fact, the $\mathrm{P}^{3}$-absent group did show a larger $\mathrm{P}^{4}-\mathrm{M}^{3}$ length relative to the palatal length than the $\mathrm{P}^{3}$-present group (Fig. 2). Thus, the discrepancy between postcanine teeth size and jaw size is correlated with $\mathrm{P}^{3}$ loss in the musk shrew. However, not all individuals with small postcanine teeth relative to jaw size lose $\mathrm{P}^{3}$, because when the $\mathrm{P}^{4}-\mathrm{M}^{3}$ length was plotted against palatal length (Fig. 2), there was overlap between the $\mathrm{P}^{3}$-absent and $\mathrm{P}^{3}$-present groups. Their difference was only based on average dimensions.

For $\mathrm{P}^{4}-\mathrm{M}^{3}$ and palatal lengths, the slopes and Y-intercepts of the $\mathrm{P}^{3}$-present group on Okinawa resembled those on Taiwan (Fig. 2), indicating that shrews with $\mathrm{P}^{3}$ present on both sides can be recognized as one allometric group. This sample showed almost the same a negative allometric slope as the $\mathrm{P}^{3}$-absent group. These findings appear to show the result that the $\mathrm{P}^{3}$-absent group had a larger Y-intercept than the group with $\mathrm{P}^{3}$ present on both sides of the jaw (Fig. 2). Since all slopes show a negative allometry (Fig. 2), $\mathrm{P}^{4}-\mathrm{M}^{3}$ relative to palatal size tends to be smaller in larger individuals. Because Taiwanese shrews have much larger palates than do Okinawa shrews (Natori and Shigehara 1993), the musk shrew on Taiwan has much more space available for $\mathrm{P}^{3}$ eruption than do the shrews on Okinawa. This situation may have led to the presence of $\mathrm{P}^{3}$ in all specimens from Taiwan. On the other hand, the Okinawa population, having small palates (Natori and Shigehara 1993), seems not to have enough room for $\mathrm{P}^{3}$ eruption. Individuals with extremely small space may often lose $\mathrm{P}^{3}$, which then results in a larger Y-intercept of for $\mathrm{P}^{3}$-absent group in the allometric relationship than do the group with $\mathrm{P}^{3}$ present on both sides.

\section{References}

Abe H. 1958. Individual and age variations in two species of genus Sorex, Insectivora in Hokkaido. Journal of Faculty of Agriculture, Hokkaido University 3: 201-209. [In Japanese with English summary] 
Allen G. M. 1938. Mammals of China and Mongolia. Natural History of Central Asia. The American Museum of Natural History, New York: 1-620.

Dahlberg A. A. 1949. The dentition of the American Indian. [In: The physical anthropology of the American Indian. W. S. Laughlin, ed]. Viking Fund, New York: 138-176.

Frisch J. E. 1965. Trends in the evolution of the hominoid dentition, Bibliotheca Primatologica, Face. 3. S. Karger, Basel: 1-130.

Gould S. J. 1975. On the scaling of tooth size in mammals. American Zoologist 15: 351-362.

Gregory W. K. 1921. The origin and evolution of the human dentition: a paleontological view. Part V. Later stages in the evolution of human dentition; with a final summary and a bibliography. Journal of Dental Research 3: 87-228.

Hall E. R. 1940. Supernumerary and missing teeth in wild mammals of the orders Insectivora and Carnivora, with some notes on disease. Journal of Dental Research 19: 103-143.

Hanamura H. 1985. Digestive system. [In: Suncus murinus. K. Kondo, ed]. Japan Scientific Societies Press, Tokyo: 210-228. [In Japanese with English summary]

Hanamura H., Sakai T., Toda Y. and Suzuki S. 1978. A morphological study on the dentition of Suncus murinus riukiuanus. Journal of Growth 18: 28-37. [In Japanese with English summary]

Inoue N. 1980. Tooth to denture base discrepancy in human evolution. Journal of Anthropological Society of Nippon 88: 69-82. [In Japanese with English summary]

Isomura G., Yoshizawa M. and Oda S. 1984. Osteology of the musk shrew (Suncus murinus). Anatomischer Anzeiger Jena 155: 131-141.

Kay R. F. 1975. Allometry and early hominids. Science 89: 6-64.

Kraus B. S., Jordan R. E. and Abrams L. 1980. Dental anatomy and occlusion. Williams \& Wilkins, Baltimore/London: 1-317.

Louch C. D., Ghoush A. K. and Pal B. C. 1966. Seasonal changes in weight and reproductive activity of Suncus murinus in West Bengal, India. Journal of Mammalogy 47: 73-78.

Martin R. D. 1990. Primate origins and evolution. A phylogenetic reconstruction. Chapman and Hall, London: 1-804.

Natori M. and Shigehara N. 1993. A craniometircal analysis of geographical difference between Musk shrew (Suncus murinus) on the Okinawa and Taiwan Islands. Journal of Growth 32: 47-51. [In Japanese with English summary]

Pucek Z. 1963. Seasonal changes in the braincase of some representatives of the genus Sorex from the Palearctic. Journal of Mammalogy 44: 523-53.

Sharma D. R. 1958. Studies on the anatomy of the Indian insectivore, Suncus murinus. Journal of Morphology 102: 427-553.

Shea B. T. and Gomez A. M. 1988. Tooth scaling evolutionary dwarfism: an investigation in allometry in human Pygmies. American Journal of Physical Anthropology 77: 117-132.

Shigehara N. 1980. Epiphyseal union and tooth eruption of the Riukiu musk shrew, Suncus murinus, in captivity. Journal of Mammalogical Society of Japan 8: 151-159.

Sokal R. R. and Rohlf F. J. 1981. Biometry. W. H. Freeman and Company, New York: 1-859.

Taylor R. M. S. 1982. Aberrant maxillary third molars-morphology and developmental relations. [In: Tooth. B. Kurtén, ed]. Columbia University Press, New York: 64-74.

Received 22 April 1996, accepted 21 October 1996. 